\title{
A Research on the Difficulties and Countermeasures of the Traditional Business under the Background of Mobile Internet
}

\author{
Xiurong Huang, Yaojia Huang \\ School of Business Administration, South China University of Technology, Guangzhou, China \\ Email: hxiurong266@foxmail.com
}

Received 28 September 2015; accepted 24 October 2015; published 27 October 2015

Copyright (C) 2015 by authors and Scientific Research Publishing Inc.

This work is licensed under the Creative Commons Attribution International License (CC BY). http://creativecommons.org/licenses/by/4.0/

(c) (i) Open Access

\begin{abstract}
The purpose of this paper is to provide countermeasures of the traditional business under the background of mobile internet, so that they can successfully achieve offline to online (hereinafter referred to as 020) transformation. Firstly, the article analyzes the status quo and difficulties of traditional business about operations of WeChat public account. Secondly, the article analyzes the advantages of local life service 020 from four aspects: market environment, platform, brand and industry. Finally, four countermeasures are put forward: publish quality content, clear profit model and dock data to form an 020 ecological circle efficiently.
\end{abstract}

Keywords

Traditional Business, Mobile Internet, WeChat Public Platform, Transformation Strategy

\section{Introduction}

Mobile Internet is the product of the integration of mobile and Internet, not simply adding, but multiplication-Mobile Internet $=$ mobile $*$ internet. Mobile Internet has inherited the advantages of mobile and Internet sharing, open and interactive, which is the "upgraded version" of mobile and Internet, and the Mobile Internet is the next generation of the Internet-web3.0. Since the advent of iPhone, mobile intelligent terminal will start a wide range of Mobile Internet wave sweeping the globe, and there is a growing trend. On the one hand, the unprecedented prosperity of the market environment brings enterprise a great business opportunity; "Internet plus" arises at the historic moment. On the other hand, Mobile Internet changes business forms as a lever in a great 
extent. Traditional business is very concerned about as a main part of business, because a large number of traditional businesses and the traditional businesses occupy the line of the entrance with a huge traffic. Therefore, if the traditional businesses can successfully achieve $\mathrm{O} 2 \mathrm{O}$ transformation, the development of Mobile Internet economy will be promoted.

At present, a small part of the traditional businesses with mobile Internet achieves a leap, but most of the traditional businesses are not good to meet the challenges, because they are limited to their own resources and other reasons. In view of this, in order to help traditional businesses to better realize the transformation, this paper takes the representative of the Mobile Internet-WeChat as the breakthrough point, analyzes the current situation and predicament of traditional businesses, and then analyzes the feasibility of the traditional business transformation, and finally puts forward the corresponding countermeasures.

\section{The Current Situation and Predicament of Traditional Business in WeChat Operation}

The method of market investigation was used in this paper by selecting 50 WeChat public accounts randomly. We analyzed different industries including housekeeping, washing, beauty, massage, community, takeaway, education, rental car, and so on by analyzing the operation of those public accounts in the last three months. It was found that a large number of the public accounts have following issues, such as the homogenization of content, single marketing method, loss of data, no interaction with audience, etc. High quality public accounts are rare, such as P \& G life, BESTORE, E-wash.

Homogenization of content: The survey found that $78 \%$ of the WeChat public accounts are just as a "content transportation”, copying content from network or other public accounts and pasting to users. This kind of public account has no deep thinking and understanding about enterprise itself. Besides, few original article is created and the pasting articles have no contact with enterprise itself. Enterprises have no special operations team to maintain public accounts. In other words, the maintenance of the public account is only a part-time job for their staffs. Employees cannot get any incentives from operating a public account, such as performance and wages. Therefore, the staff who operates a public account will be slack. At the same time, the article with a high degree of recognition is often copied by some similar public account at the same moment. As time passes, users are easy to be "reading fatigue". As a result of that, they will lose interested in the public account.

Single marketing method: In 1960, an American scholar E. J. McCarthy proposed the famous 4P marketing strategy combination theory, namely product strategy, price strategy, place strategy and promotion strategy [1]. Through in-depth investigation of 50 traditional companies' public accounts, it was found that a lot of marketing strategies are lack of pertinence and innovation because companies always apply same marketing strategy such as prize draw, discounts and other common ways. In addition, there are companies apply improper ways such as click "like" and swing to attract users to following their public accounts in order to junk messages, such as some advertisements. The rate of users gone is usually higher in the public account.

Loss of data: WeChat public platform specifically set up statistical module including user analysis, graphic analysis, message analysis and interface analysis, which is for statistical and inductive user data. But since companies are not expert and concerned about the user data, some traditional companies don't make use of statistical results at the greatest extent. Traditional companies are always busy on their offline business, ignoring their Wechat public accounts, so that they upload articles hastily. Therefore, they can't make precision marketing strategy.

No interaction with audiences: The growth of WeChat public accounts has been rapid, which offers many options for audiences. The relationship between public accounts and audiences is like friendship. Companies need to maintain the relationship via regular interactions. In this paper, we sent the product inquiry to 50 public accounts. As a result, there were 6 public accounts replied within 24 hours, 11 accounts replied within 48 hours, and the rest of them didn't reply. The phenomenon showed that a lot of the traditional companies were lack of interactive awareness. They thought that the public account was only used to upload articles and didn't care about the sentiments of audiences. Once the audiences are perceived to be ignored, the frequency of stickiness will be reduced.

In addition, there is a variety of problems of the WeChat public accounts for traditional companies: no update articles for a long time, articles layout disorder and irrespective content, which will increase the rate of losing audiences. 


\section{Advantages of 020 of Local Life Service}

In 2010, founder of Trial Pay-Rampell Alex raised the concept of O2O for the first time. He believes that, through looking for consumers online, the model then provides them an experience offline in order to promote the development between online and offline business. Ultimately the model achieves information flow and capital flow by online and service flow and commercial flow by offline [2]. In recent years, as development of Internet has been thriving, WeChat, for which the companies have always contended, is pushed up onto the top of the hottest-apps ranking list, having a strongly binding effect on consumers. Under such a circumstance, the traditional businesses who own a large number of offline entrance grasp their own unique advantages.

\subsection{The Advantage of Market Environment}

2014 is the first year of O2O. Internet giants have set up layout for O2O. Hairdressing, food, clothing and other traditional industries are gradually commercialized in the field of Mobile Internet. At the same time, the $\mathrm{O} 2 \mathrm{O}$ is given boundless imagination with the maturity of mobile payment. Wu Wei, vice president of "i Research", has reported that the 2014 local $\mathrm{O} 2 \mathrm{O}$ market size is 2350 billion yuan, in which food accounted for about $40.1 \%$, being the relatively highest. In 2014 the network market size is 1.85 trillion. The permeability of $\mathrm{O} 2 \mathrm{O}$ in local life is still at a comparatively low level, nonetheless there will be more local life services entering the internet in 2015 [3].

\subsection{The Advantage of Platform Maturity}

In 2011, John Doerr, a famous venture investor, first proposed the concept of "SoLoMo", considering that "Social", "Local", "Mobile" will be the trend of the future of $\mathrm{O} 2 \mathrm{O}$ [4]. WeChat, as an open platform, after updating for 5 years, has become a strong app which can alter the industrial pattern of the Internet and has incomparable advantages that other apps do not have. Local businesses can easily create a WeChat public account (including subscription account and service account) to attract consumers through online propaganda or offline QR code. Propagandizing the product can be turned into the online consumers. At the same time, by using coupons and VIP Card to lead consumers get into the real store to consume and experience, it will form a an $\mathrm{O} 2 \mathrm{O}$ ecological circle. During the process, to manage user data and to analysis basic information, such as consumer time, consumer sites etc. of a consumer can be used again to accurate marketing and get a higher conversion rate of consumers. Different from the traditional e-commerce model, the $\mathrm{O} 2 \mathrm{O}$ business model which is established on the foundation of WeChat makes the local companies join the mobile Internet competition so that local companies are able to serve for the consumers anywhere.

\subsection{The Advantage of Brand Accumulation}

Compared to the Internet brand, the traditional business has profounder accumulation of brand than the Internet brand does. When consumers face a newly online brand and familiarly old brand, they will choose the later one without hesitating. If a certain well-known brand offline, such as BESTORE with million members, implemented sales online, consumers do not have any doubt about the quality of the products, which the new brands are not able to ensure. At the same time, consumers once approved the brand; do not care about the price of the product in the same kind. Overall, the traditional brand has been recognized by the vast number of consumers, the consumer's trust costs greatly reduced through the network, the conversion rate of audience can be higher, and the brand value can be greater.

\subsection{The Advantage of Industry Cognition}

New enterprises are springing up in the era of Mobile Internet and how to stand in an invincible position in a large number of competitors is the most important problem of traditional business. It will undoubtedly be the next NOKIA if handled improperly. With many years of experience in the industry, the traditional business to grasp the product supply chain, consumer data and other important information, they have a more profound understanding about the industry. Therefore, the cost of trial and error of the traditional business is far lower than a new brand online in the Mobile Internet era. Traditional businesses should dare to subvert their own and innovative business model to meet consumer demand, then ushered in their own spring in the Mobile Internet era with its advantages in the field of cognitive and experience in the industry. 


\section{Analysis on 020 Strategy of Local Life Service}

The industry and academia concern about the rise of Mobile Internet economy based on the WeChat platform of local life service $\mathrm{O} 2 \mathrm{O}$. O2O business model not only needs to be integrated with O2O, mobile payment, LBS (based on the service of location) and other factors, but also to address the challenges from the management, organization, marketing and so on [4]. In the wave of mobile Internet, many traditional businesses are limited by these difficulties, the lack of awareness of the market opportunity resulting in only the name of the mobile Internet carrier but no corresponding real profits. In view of this, the following will propose some building strategy for the traditional business of WeChat $\mathrm{O} 2 \mathrm{O}$ transformation.

\subsection{Publish Quality Content: Adhere to Be Original, Mining Users' Preference Deeply}

At present, the WeChat public platform is lack of quality accounts and a lot of public accounts only reproduced or copied some content of the network. WeChat public platform is different from the traditional media, the content must be original if they want to win the victory, so it is important to do the editors and operations of public account. The number of users has their own preferences on the articles, form, time, etc. Therefore the traditional business should excavate deeply in some aspects: techniques for selecting topics (select hot topics, dig local features), title production (transfer the article theme in brief, should not blindly follow suit, exaggerate the facts), communication forms (text, pictures, audio, video) [5], release time (select the time such as noon, evening) and other aspects. The traditional business must achieve better publicity effect from understanding user preferences.

\subsection{Clear Profit Model: From High Frequency-Low per Customer to Low Frequency-High per Customer}

Most of the local service life businesses have not yet to find the suitable profit model. A solution is that soliciting customers' flow through "high frequency-low price", and then completing the requirements of commercial through the "low frequency-high price".

Take the "ele.me” for example, ele.me originated in Minxing Campus of Shanghai Jiaotong University, it pay attention to student market from the beginning of the creation. As of October 2014, the business of ele.me covered nearly 200 cities nationwide, it joined the number of restaurants near 180,000, the average daily order of ele.me more than $1,000,000$, team size more than 2000. Student market is a typical "high frequency-low price" market. Students are a large group, ordering behavior occurs very frequently, it is a high-frequency market, but students' income is relatively low, lead to a lower per customer price. At present, the ele.me only in the individual a second tier cities to cover the residential area, in the three or four line of the city is still dominated by students market. From the second half of 2014, ele.me trys to win the white collar consumers. Relative to the students at the level of about 15 yuan per meal, white-collar workers were significantly higher, but due to whitecollar workers on the dishes, services, logistics and other aspects have more requirements, ele.me it is also starting logistics itself. It tries to seize the high-end catering takeaway market from changing the existing operating mode, finally to complete the commercial operation.

In addition to ele.me, there are many excellent local life O2O business: "home cuisine", "to hi friends," "beaver" and "E-wash" and so on. With the development of O2O mode of WeChat public platform, There will be more outstanding enterprises in various industries expected in the future.

\subsection{Docking Data Efficiently: Docking Data Efficiently Online and Offline to Achieve Precision Marketing}

The IT level of local life service businesses is usually low, businesses can put the user data on the platform using WeChat public account. WeChat public platform specifically set up statistical module, including the user analysis, graphic analysis, message analysis and interface analysis. The user is classified by sex, language, province, city, terminal and model of mobile phone, the analysis module of user is able to increase the growth trend. After the analysis, businesses can easily access to data of text reading, forwarding and collecting, then businesses will get more understanding of users’ preferences to push more messages that audience like. Message analysis module can statistic the interaction information of the audience and the WeChat public platform, businesses can find the rule based on statistical data, thereby enhancing interaction with them. Interface analysis is mainly for the use of statistical analysis of the public platform from the technical level. 
It is not enough deep to analyze user data through the WeChat public platform, businesses could use thirdparty service providers of WeChat to achieve data linkage between online and offline. Take the "BESTORE" for example, BESTORE has a high visibility brand of the leisure food chain, it had 100 million member entities before O2O, but BESTORE still faces some difficulties such as hard to marketing precisely, low loyalty of customer, high cost of customer maintenance. Then BESTORE figure out a way to get away from the situation. It hired Adsit, a third-party service provider, for its design of the public account. The account has successfully achieved user binding, user classification, labeling and accurate marketing, communication online one to one, interactive with game, membership points system established etc. Thanks to the user data, the user's satisfaction are greatly enhanced with precision marketing services, the sales have been greatly improved with $\mathrm{O} 2 \mathrm{O}$ diversion.

\subsection{Forming an 020 Ecological Circle: Marketing Linkage between Online and Offline, Security Pay Is Essential to 020}

If there is no product or service to support $\mathrm{O} 2 \mathrm{O}$ business model, user stickiness will be greatly reduced. Therefore, a physical shop with high quality is necessary. April 2015, Ajisen Ramen carried out the preferential service from scanning code in various physical stores. Once a person became an audience of its WeChat public account, Ajisen Ramen added a piece of cut pork and half a runny eggs as a reward. Due to the superior quality, unique taste, quality service and high network flow of Ajisen Ramen, audiences guided to online are stable and high adhesiveness.

On the other hand, WeChat public account should provide preferential information as well as the security payment to offline shop, forming an $\mathrm{O} 2 \mathrm{O}$ ecological circle. The ultimate goal of consumer diversion to the online is to achieve the conversion of audience to customers. Businesses provide incentives, promotions and other information to user will lead audience to the offline shop from the WeChat public account, so as to improve sales. At the same time, an important goal of the local life $\mathrm{O} 2 \mathrm{O}$ is to form an ecological circle, online payment is an essential link. Most businesses such as "ele.me", WeChat public account has been achieved online payment and formed an $\mathrm{O} 2 \mathrm{O}$ ecological circle.

\section{Conclusion}

Although the traditional business has a natural advantage in the process of $\mathrm{O} 2 \mathrm{O}$ transformation, but they still face with the same content: single marketing model, data loss, audience fault and other difficulties. Traditional businesses must deal with its accurate positioning, if the enterprise is suitable for $\mathrm{O} 2 \mathrm{O}$ transformation, through the following methods to reduce the cost of trial and error: publishing high quality content; adhering to the original; clearing profit model; setting low frequency and high customer price as a goal; dock data efficiently tagging precision marketing to audiences; interaction between online and offline forming a completed $\mathrm{O} 2 \mathrm{O}$ ecological circle. However, if the enterprise is not suitable for $\mathrm{O} 2 \mathrm{O}$ transformation, they should be cautious and actively seek a more suitable business model.

\section{References}

[1] Perreanlt, W.D. and·McCarthy, E.J. (2006) Basic Marketing. Shanghai People’s Publishing House, Shanghai.

[2] Zhang, B. (2013) O2O: Mobile Internet Era of Business Revolution. Machinery Industry Press, Shanghai, 7-15.

[3] iResearch (2014) O2O Report of the China Internet Community Summit Forum.

[4] Li, H.Y. (2014) Thinking and Practice Path of Traditional Enterprise O2O Business. Modern Business Trade Industry, 11, 20-22.

[5] Wang, H.Y. (2015) Analysis on Editing and Operational Strategies of Traditional Media WeChat Public Number. Editorial Friend, 2, 85-88. 